\title{
Multicolor microcontact printing of proteins on nanoporous surface for patterned immunoassay
}

\author{
Elaine Ng • Ashwini Gopal · Kazunori Hoshino • \\ Xiaojing Zhang
}

Received: 10 April 2011 / Accepted: 11 April 2011/Published online: 27 April 2011

(C) The Author(s) 2011. This article is published with open access at Springerlink.com

\begin{abstract}
The large scale patterning of therapeutic proteins is a key to the efficient design, characterization, and production of biologics for cost effective, high throughput, and point-of-care detection and analysis system. We demonstrate an efficient method for protein deposition and adsorption on nanoporous silica substrates in specific patterns using a method called "micro-contact printing". Multiple color-tagged proteins can be printed through sequential application of such micro-patterning technique. Two groups of experiments were performed. In the first group, the protein stamp was aligned precisely with the printing sites, where the stamp was applied multiple times. Optimal conditions were identified for protein transfer and adsorption using the pore size of $4 \mathrm{~nm}$ and thickness of $30 \mathrm{~nm}$ porous silica thin film. In the second group, we demonstrate the patterning of two-color rabbit immunoglobin labeled with fluorescein isothiocyanate and tetramethyl rhodamine iso-thiocyanate on porous silica substrates that have a pore size $4 \mathrm{~nm}$, porosity $57 \%$ and thickness of the porous layer $30 \mathrm{~nm}$. A pair of protein stamps, with corresponding alignment markings and coupled patterns, were aligned and used to produce a twocolored stamp pattern of proteins on porous silica. Different colored proteins can be applied to exemplify the diverse protein composition within a sample. This method of multicolor microcontact printing can be used to perform a fluorescence-based patterned enzyme-linked immunosorbent assay to detect the presence of various proteins within a sample.
\end{abstract}

E. Ng $(\bowtie) \cdot$ A. Gopal $\cdot$ K. Hoshino $\cdot$ X. Zhang

Department of Biomedical Engineering, The University

of Texas, Austin, TX 78758, USA

e-mail: elaine_ng@mail.utexas.edu
Keywords Multicolor - Microcontact printing · Patterned immunoassay $\cdot$ Nanoporous

\section{Introduction}

Microcontact printing $(\mu \mathrm{CP})$ is a method in which a stamp is "inked" with specific molecules with subsequent deposition of those molecules onto a substrate with wellcontrolled pattern. Such a technique was first demonstrated in the patterning of alkanetholate self-assembling monolayers (SAMs) on gold substrates (Kumar et al. 1994). Since then, $\mu C P$ has been extended to incorporate many applications, including the patterning of functional proteins for immunoassays and biosensors (Bernard et al. 2000; Pattani et al. 2008). Furthermore, to enhance the diagnostic power of immunoassays, multiple proteins can be patterned on the same substrate and has been demonstrated in a variety of ways (Inerowicz et al. 2002; Crozatier et al. 2006; Ghosh et al. 2008). The ability to print multiple proteins on a single substrate and on such a small scale is important in creating an efficient point of care detection and analysis systems.

Enzyme-linked immunoabsorbent assay (ELISA) is a technique used to detect the presence of specific antibodies or antigens in a sample ( $\mathrm{Li}$ et al. 2008). There are many different types of ELISA, however, the sandwich ELISA technique described here will be most applicable to the investigation. It involves affixing an amount of antigen to a surface specifically via a capture antibody and then washing the surface with a specific primary antibody. The antigen binds to the primary antibody. The surface is washed with a second solution containing an enzymelinked secondary antibody. The primary antibody is linked to the enzyme-linked secondary antibody. Upon the 
addition of a particular substrate, the enzyme is converted to a detectable signal. For example, in fluorescence ELISA, when light of a specific wavelength is shone upon the sample, the antigen-antibody complexes will fluoresce and the amount of antigen in the sample can be inferred by the magnitude of the fluorescence. Typical ELISA testing requires long procedures; involving the use of microliter well plates as well as generous amounts of reagents for each immunoassay performed, and quantified using spectrophotometry comparisons with standards ( $\mathrm{Li}$ et al. 2008; Rolland et al. 2008; Stephan and Vieths 2004; Sun et al. 2010). Applications of ELISA include use in the food industry to detect food allergens such as milk, nuts, and eggs (Rolland et al. 2008; Stephan and Vieths 2004).

In this paper, we demonstrate an efficient method for the deposition and adsorption of two different color-tagged proteins on a single nanoporous silica substrate through sequential application of the $\mu \mathrm{CP}$ technique. Furthermore, we demonstrate the application of multicolor $\mu \mathrm{CP}$ for multiple antigen detection in immunoassays by performing a sandwich ELISA for the simultaneous detection of two common allergens, ovomucoid found in egg white, and casein found in milk. The ability to microcontact print and detect multiple antigens in a single sitting, coupled with fluorescence optical detection and quantification, has the potential to lay grounds for more efficient immunoassays and biosensors. The ability to also miniaturize and microscale the immunoassay itself enables wider, more cost efficient, varieties of biomedical point of care applications.

\section{Experimental procedures}

Fabrication of porous silica substrates

It has been shown that substrates functionalized with a nanoporous silica thin film can be used to enhance protein adhesion and adsorption onto the substrate surface through physical means (Hu et al. 2009), more so than surfaces functionalized by chemicals such as 3-aminopropyltriethoxysilane (APTES) or glutaraldehyde (GA) (Blinka et al. 2010). All experimentations described in this paper used nanoporous silica thin film functionalized substrates characterized by $4 \mathrm{~nm}$ pores, $56 \%$ porosity, and 30-100 nm thickness for optimal protein adsorption and adhesion. These characterizations along with the nanoporous silica substrate fabrication process are detailed in a paper by Blinka et al. (2010). Figure 1 shows the schematic for nanoporous silica substrate fabrication. The nanoporous and rough surface of the substrate enhances absorption of proteins by increasing the surface area of contact between protein and substrate. In general, a polymer-silicate coating solution was prepared and spin coated onto glass or silicon

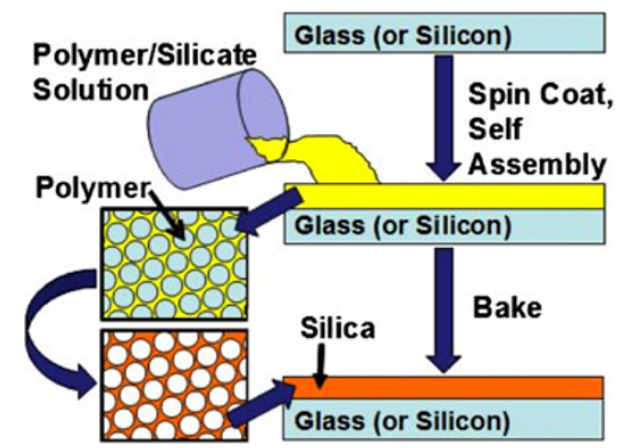

Fig. 1 Schematic of the fabrication of nanoporous silica substrates (Hu et al. 2009)

substrate. The evaporation of solvent during spin coating drives the formation of a silica-copolymer SAM of thin film nanoscale dimensions. Pore sizes, thickness of the film, and porosity of the film could be tuned through the molar ratio of silicate to polymer and deposition rates.

Multicolor microcontact printing

Poly(dimethylsiloxane) (PDMS) stamps were fabricated from hard silicon masters (Schmid and Michel 2000) with $100 \mu \mathrm{m}$ diameter by $20 \mu \mathrm{m}$ high circular patterns and four corner alignment marks. The circular pattern on the two separate stamps of a set alternated so that when aligned correctly using the alignment marks, will form an alternating pattern (ABABAB). Stamps with pattern $\mathrm{A}$ was inked with a $5 \mu \mathrm{g} \mathrm{mL}^{-1}$ FITC-tagged (fluorescein isothiocyanate) anti-rabbit $\operatorname{IgG}$ (Sigma-Aldrich) solution for 20 min. Stamps with pattern B was inked with a $5 \mu \mathrm{g} \mathrm{mL}^{-1}$ TRITC-tagged (tetramethyl rhodamine isothiocyanate) anti-rabbit IgG (Sigma-Aldrich) solution for $20 \mathrm{~min}$. Both stamps were washed with $0.01 \mathrm{M}$ phosphate buffer saline solution (PBS) and de-ionized water and dried under nitrogen $\left(\mathrm{N}_{2}\right)$ gas. Figure 2 shows the basic schematic for $\mu \mathrm{CP}$ of a single protein onto nanoporous silica substrate. Stamps A and B were sequentially brought into contact with the nanoporous silica substrate for $1 \mathrm{~min}$. Printing was done manually using a home-built stamping apparatus with a stamp-carrying part capable of micrometer level translation in the $x, y$, and $z$ direction, to allow alignment precision within $5 \mu \mathrm{m}$. In order to align the stamps and create a patterned substrate of the two different proteins, alignment markings on both stamps were aligned with corresponding alignment markings on the substrate. To visualize the alignment of the stamp with the substrate, a microscope was positioned above the apparatus. Figure 3 shows the schematic for multiple $\mu \mathrm{CP}$. Transferred protein layers were analyzed by fluorescence (Olympus BX51) and atomic force microscopy (AFM; Digital Instruments Series 


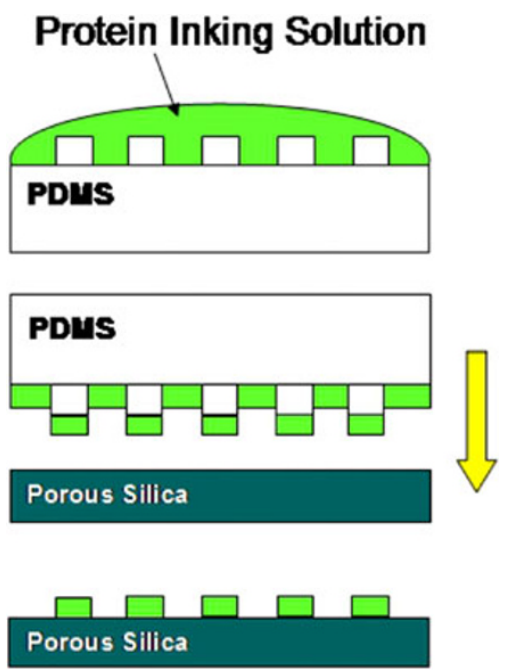

Fig. 2 Schematic of the microcontact printing process

IV, Veeco) for surface thickness and roughness to show monolayer deposition of proteins.

Application of sandwich enzyme-linked immunoabsorbent assay

The concept of multicolor $\mu \mathrm{CP}$ was used in an application to a sandwich ELISA detection of two different common food allergens, ovomucoid in egg white and casein in milk.

\section{Protein sample extraction}

A white hen egg (Hill Country) was purchased from a local grocery store, cracked, and the egg yolk was separated from the egg white. The egg white was diluted in PBS to form a $25 \mu \mathrm{g} \mathrm{mL}^{-1}$ solution. Skim milk (Oak Farm) was purchased from a local grocery store. The milk was heated to $40^{\circ} \mathrm{C}$ and reacted with $2 \%$ vinegar (acetic acid) in a drop by drop technique to separate the two milk proteins, whey and casein. The whey was discarded and the casein was diluted in PBS to form a $25 \mu \mathrm{g} \mathrm{mL}^{-1}$ solution. Both egg white and milk solutions were then subjected to heated ultrasonification using an ultrasonic cleaner (Crest 275) to further break down the sample into a uniform solution.

\section{Microcontact-printed sandwich ELISA}

Stamps with one pattern (A) of $100 \mu \mathrm{m}$ circles were inked with a $5 \mu \mathrm{g} \mathrm{mL}^{-1}$ mouse anti-chicken ovomucoid (Cosmo Bio) capture antibody solution for $20 \mathrm{~min}$. Stamps with a second pattern (B) were inked with a $5 \mu \mathrm{g} \mathrm{mL}^{-1}$ mouse anti-casein kinase 1, $\gamma 1$ (Sigma-Aldrich) capture antibody solution for $20 \mathrm{~min}$. Both stamps were washed with $0.01 \mathrm{M}$ PBS solution and de-ionized water and dried under $\mathrm{N}_{2}$ gas. Alignment of the stamps with the substrate surfaces and printing was done manually using the home-built stamping apparatus facilitated by a microscope positioned above the apparatus. Stamp A was brought into contact with one nanoporous silica substrate (A) and B, with a separate (B), for $1 \mathrm{~min}$.

To prevent non-specific binding, $20 \mu \mathrm{L}$ of $5 \%$ bovine serum albumin (BSA) solution was pipetted onto the surface of the substrates over the protein stamped area in a blocking step. The samples were incubated overnight at $4^{\circ} \mathrm{C}$ and then triple washed at $5 \mathrm{~min}$ intervals using $0.01 \mathrm{M}$ PBS solution. $20 \mu \mathrm{L}$ of the egg white sample solution was pipetted onto the surface of substrate $\mathrm{A}$ and $20 \mu \mathrm{L}$ of the milk sample solution, onto the substrate B. Both samples were incubated for $2 \mathrm{~h}$ at room temperature and then washed in the same manner as previously. $20 \mu \mathrm{L}$ of $5 \mu \mathrm{g} \mathrm{mL}^{-1}$ rabbit anti-chicken ovomucoid (Alpha Diagnostic International) primary antibody was pipetted onto
Fig. 3 Schematic of multiple microcontact printing. The alignment marks on the two stamps were aligned with corresponding alignment marks on the nanoporous silica substrate to ensure a patterning of the two different proteins

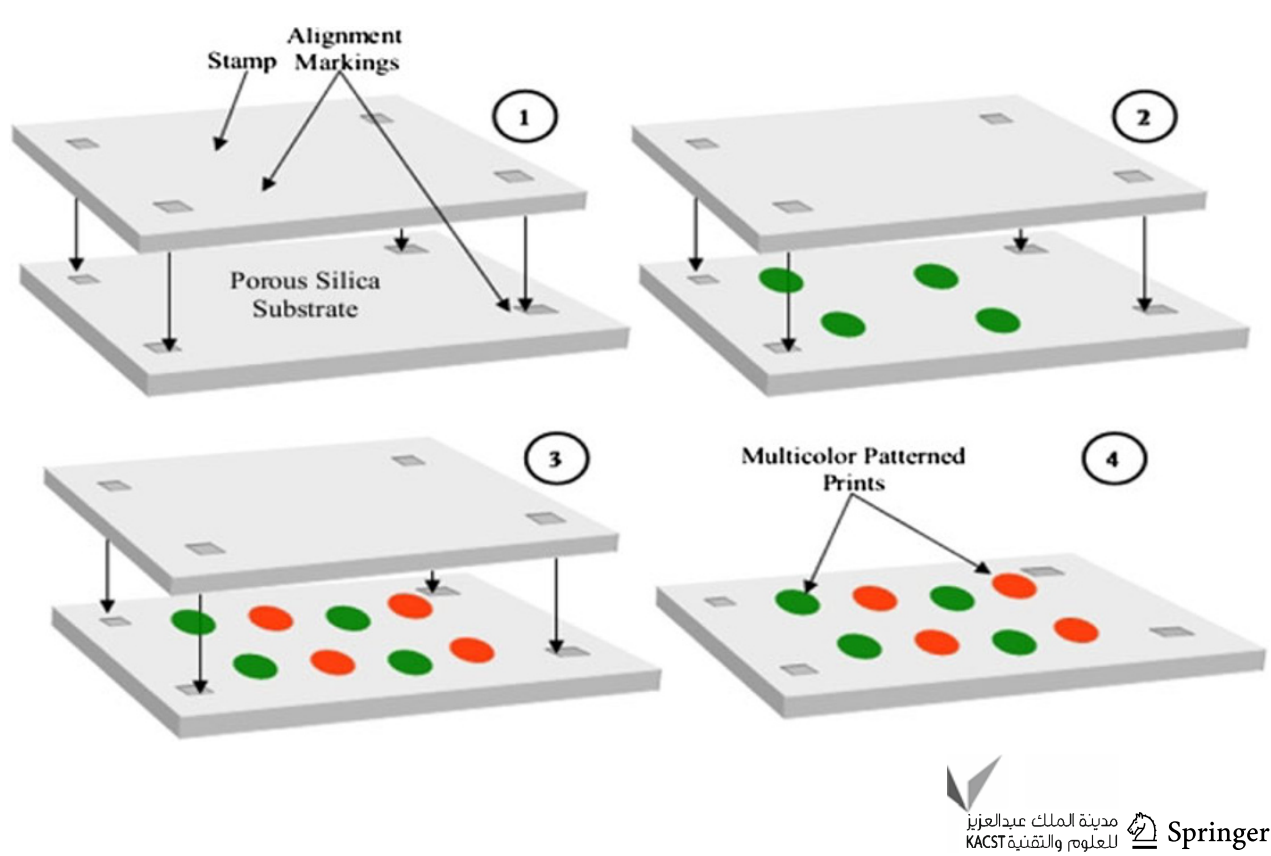


Fig. 4 a Theoretical molecular structure of a single sandwich ELISA. The ultimate binding of the detecting secondary antibody, tagged by a fluorophore, enables optical detection when excited by a light source. b Schematic of the microcontact sandwich ELISA process. The capture antibody is microcontact printed onto the nanoporous silica substrate surface. Subsequent pipetting of specific antibodies builds and completes the sandwich ELISA

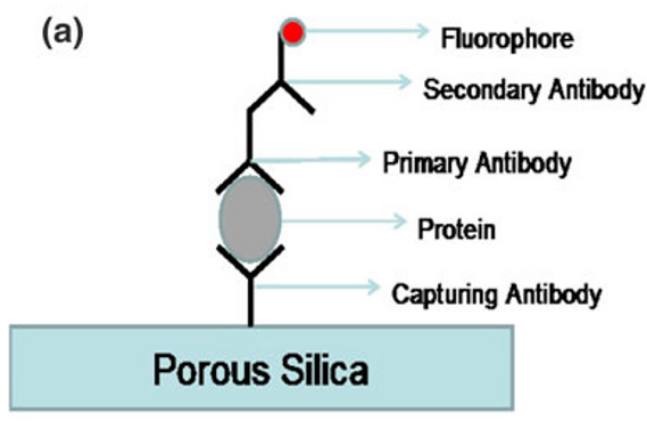

(b)

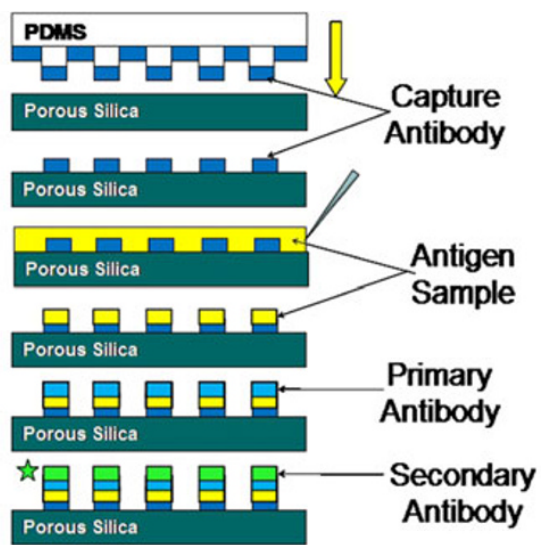

the surface of substrate A and $20 \mu \mathrm{L}$ of $5 \mu \mathrm{g} \mathrm{mL}^{-1}$ rabbit anti-casein kinase 1, $\alpha 1$ (Sigma-Aldrich) primary antibody, onto substrate B. Samples were incubated for $2 \mathrm{~h}$ at room temperature and then subjected to a washing step. $20 \mu \mathrm{L}$ of $5 \mu \mathrm{g} \mathrm{mL}^{-1}$ of FITC-tagged anti-rabbit IgG was pipetted onto the surface of substrate $\mathrm{A}$ and $20 \mu \mathrm{L}$ of $5 \mu \mathrm{g} \mathrm{mL}{ }^{-1}$ of TRITC-tagged anti-rabbit IgG, onto substrate B. Samples were incubated for $1 \mathrm{~h}$ at room temperature and then subjected to a final washing step. Figure 4 shows the schematic for microcontact-printed sandwich ELISA process and the theoretical molecular structure of a single microcontact-printed sandwich ELISA on the surface of a nanoporous silica substrate. Each substrate was viewed by fluorescence microscopy (Olympus BX51) for positive detection of component antigens.

\section{Results and discussion}

Quantification of Multicolor microcontact-printed proteins

\section{Fluorescence observations}

It was first demonstrated that two different proteins could be simultaneously microcontact printed onto a single substrate via careful manual alignment of a set of complementary stamps to the nanoporous silica substrate, facilitated by corresponding alignment markings on both stamps and substrate. The nanoporous silica substrate was put under a fluorescence microscope and excited under the FITC filter (excitation wavelength $\sim 490 \mathrm{~nm}$ ) and the TRITC filter (excitation wavelength $\sim 557 \mathrm{~nm}$ ). Both proteins fluoresced under their respective filters. Under the FITC filter, only the FITC rabbit IgG circular pattern showed positive green fluorescence, while TRITC rabbit $\mathrm{IgG}$ showed negative fluorescence. Under the TRITC filter, only the TRITC rabbit IgG circular pattern showed positive red-orange fluorescence, while FITC rabbit IgG showed negative fluorescence. This indicates successful transfer of the proteins and hence successful multicolor $\mu \mathrm{CP}$ of two different proteins on the same substrate. Figure 5 shows the resulting fluorescence microscopy pictures. As shown in the overlay, the alignment of the two stamps on the substrate was relatively precise, giving a small amount of displacement (about $30 \mu \mathrm{m}$ ). Because the stamping was manually performed and relative precision was eyeballed, there is large room for human error. Although $30 \mu \mathrm{m}$ may seem small, on a nanoscale level, it is relatively large. Future improvements to the $\mu \mathrm{CP}$ apparatus, perhaps even development of an automated apparatus, will potentially increase the precision and accuracy of alignment. However, such is beyond the scope of this paper, and as shown by the overlay, a successful multicolor multicontact printing of two different proteins was demonstrated.

\section{Quantification of printed protein layers}

The stamped protein layers were analyzed using AFM microscopy and Vernier LabPro to evaluate the consistency of the transfer of the from PDMS stamp to nanoporous silica substrate. Ten FITC protein circles and five TRITC protein circles were arbitrarily chosen on the substrate and evaluated for protein layer thickness and surface roughness. To calculate thickness data, AFM pictures were divided into regions of protein coverage and regions of background. $1 \mu \mathrm{m}^{2}$ areas were taken from the area where the regions bordered each other. For each area, the background height was subtracted from the protein layer height to get a thickness value. A similar method of calculate surface roughness was used. Figure 6 shows fluorescence and AFM images obtained from a single circle of both FITC and TRITC-labeled microcontact-printed proteins. 


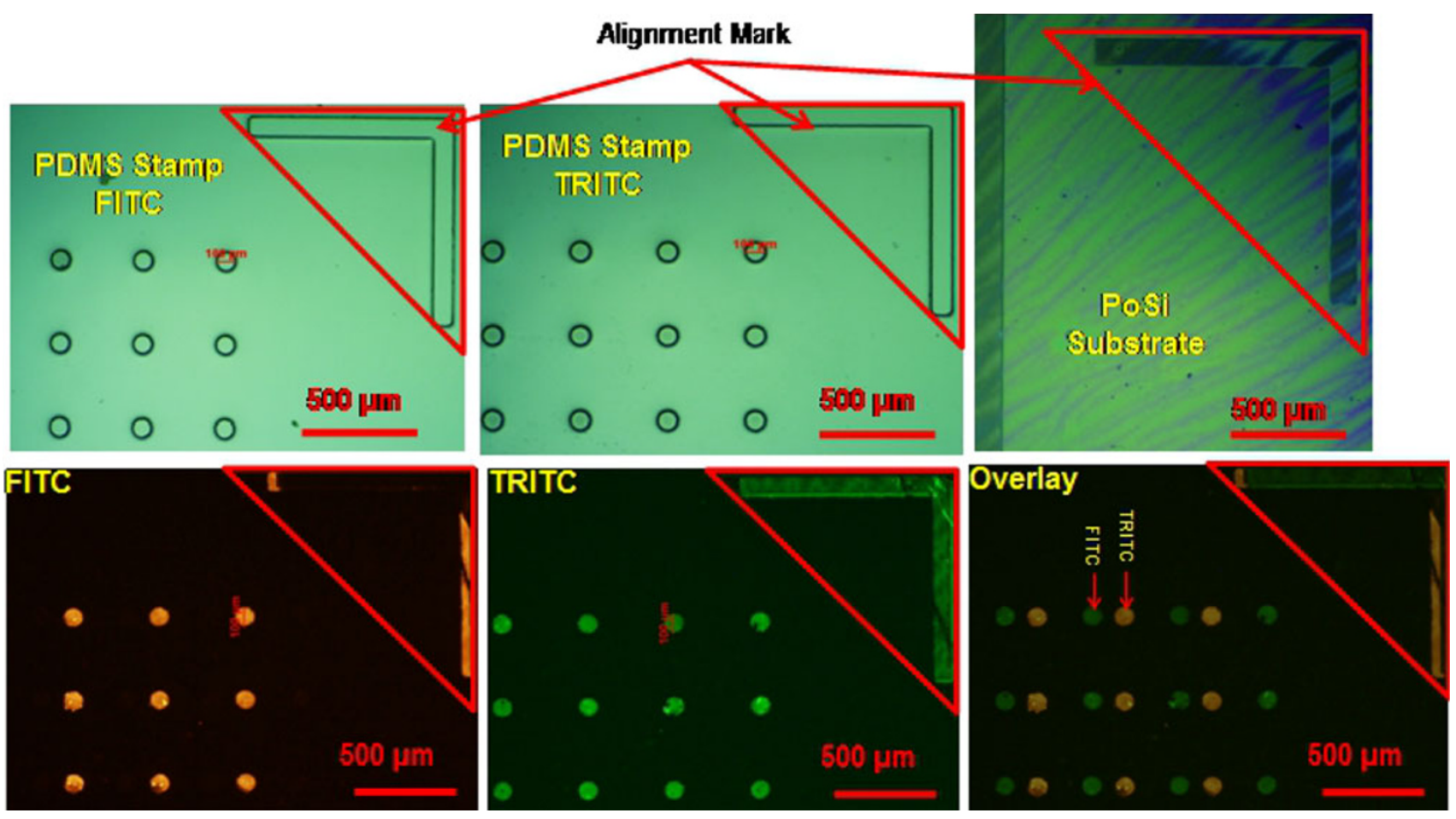

Fig. 5 Top, left to right: PDMS stamp used to stamp FITC rabbit IgG antibodies; PDMS stamped used to stamp TRITC rabbit IgG antibodies; nanoporous silica substrate. All three have corresponding alignment markings to facilitate accurate stamping. Bottom, left to right: Fluorescence microscopy pictures of substrate viewed under FITC filter; substrate under TRITC filter; overlay of the two pictures. The proteins on the substrate fluoresced under respective filters and the overlay demonstrates preciseness of alignment and no overlapping
Fig. 6 Fluorescence and AFM images of both FITC and TRITC-labeled circular microcontact-printed proteins
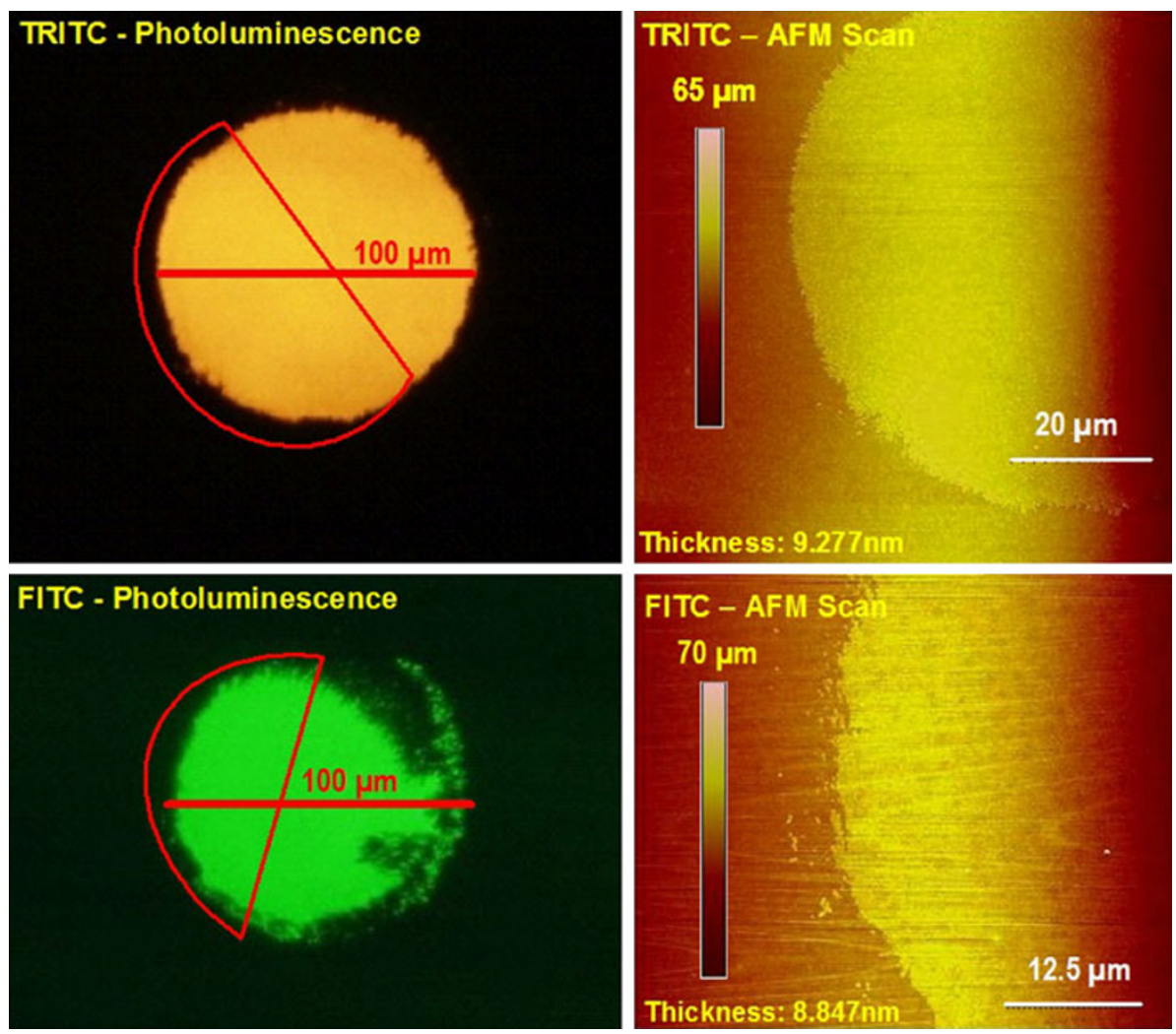

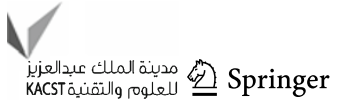


Table 1 Thickness and roughness measurements of printed proteins

\begin{tabular}{lllll}
\hline Proteins & $\begin{array}{l}\text { Number of } \\
\text { samples }\end{array}$ & $\begin{array}{l}\text { Thickness } \\
(\mathrm{nm})\end{array}$ & $\begin{array}{l}\text { Roughness } \\
(\mathrm{nm})\end{array}$ & $\begin{array}{l}\text { Standard } \\
\text { deviation }(\mathrm{nm})\end{array}$ \\
\hline TRITC & 5 & 8.496 & 0.301 & 1.064 \\
FITC & 10 & 9.271 & 0.656 & 1.075 \\
\hline
\end{tabular}

Table 1 shows the resulting overall average thickness and roughness for the FITC and TRITC proteins.

The average thickness of the FITC protein layer deposited onto the nanoporous substrate was $8.496 \mathrm{~nm}$ with a standard deviation of $1.064 \mathrm{~nm}$. The average surface roughness was $0.301 \mathrm{~nm}$. The average thickness of the deposited TRITC protein layer was $9.271 \mathrm{~nm}$ with a standard deviation of $1.075 \mathrm{~nm}$. The average surface roughness was 0.656 . The dimensions of $\operatorname{IgG}$ have been reported as $8.5 \times 14.4 \times 4 \mathrm{~nm}$ (Lee et al. 2002). The height dimensions observed for the printed protein molecules are consistent with these accepted dimensions for rabbit IgG. This indicates that the $\mu \mathrm{CP}$ method was, on average, able to consistently deposit a single monolayer of rabbit $\mathrm{IgG}$ antibodies onto the surface of the nanoporous silica substrate. Furthermore, the average surface roughness is relatively low, at most $0.66 \mathrm{~nm}$, indicating the layer deposited onto the substrate is relatively uniform and coverage (Blinka et al. 2010).

\section{Microcontact-printed sandwich ELISA}

The ability to incorporate the $\mu \mathrm{CP}$ technique to perform a sandwich ELISA on the surface of a nanoporous silica substrate was demonstrated. The detection of common allergens egg white protein ovomucoid and milk protein casein was performed. The two sample substrates were observed under a fluorescence microscope under FITC and TRITC filters. Both samples fluoresced under their respective filters indicating positive detection of the allergens and successful microcontact-printed sandwich ELISAs. FITC-detected ovomucoid fluoresced green under the FITC filter while showing negative fluorescence under the TRITC filter. TRITC-detected casein fluoresced red-orange under the TRITC filter while showing negative fluorescence under the FITC filter. The detection method was therefore successfully specific to the desired allergen under examination. Figure 7 shows the fluorescence microscopy pictures of both sample substrates.

\section{Conclusion}

In this paper, we describe a method for multicolor $\mu \mathrm{CP}$ on nanoporous silica substrate that allows for more efficient detection of multiple proteins on a single substrate with a potential of enhancing diagnostic power of immunoassays. In addition, we demonstrate the capability to perform a miniaturized sandwich ELISA to detect common food allergens, such as egg white ovomucoid and milk casein, on nanoporous silica substrate using the $\mu \mathrm{CP}$ technique. The use of nanoporous silica membranes as substrate material allows versatile surface functionalization and provides for better protein adhesion and adsorption (Blinka et al. 2010). The ability to microcontact print multiple proteins onto the same substrate surface allows for highthroughput manufacturing of compact systems with planar device structures, ideal for detection on-chip designs. Furthermore, such capability has great potential in increasing the efficiency of immunoassays, such as sandwich ELISAs, with the ability to detect two antigens simultaneously. With further extension of the multicolor $\mu \mathrm{CP}$ method described here, a sandwich ELISA of two different antigens could be conducted on the same substrate. Food samples containing both egg white and milk would be able to be detected simultaneously on the same substrate.
Fig. 7 Fluorescence microscopy pictures of the microcontact-printed sandwich ELISAs on nanoporous silica substrates. a FITC-tagged egg white ovomucoid and b TRITCtagged milk casein
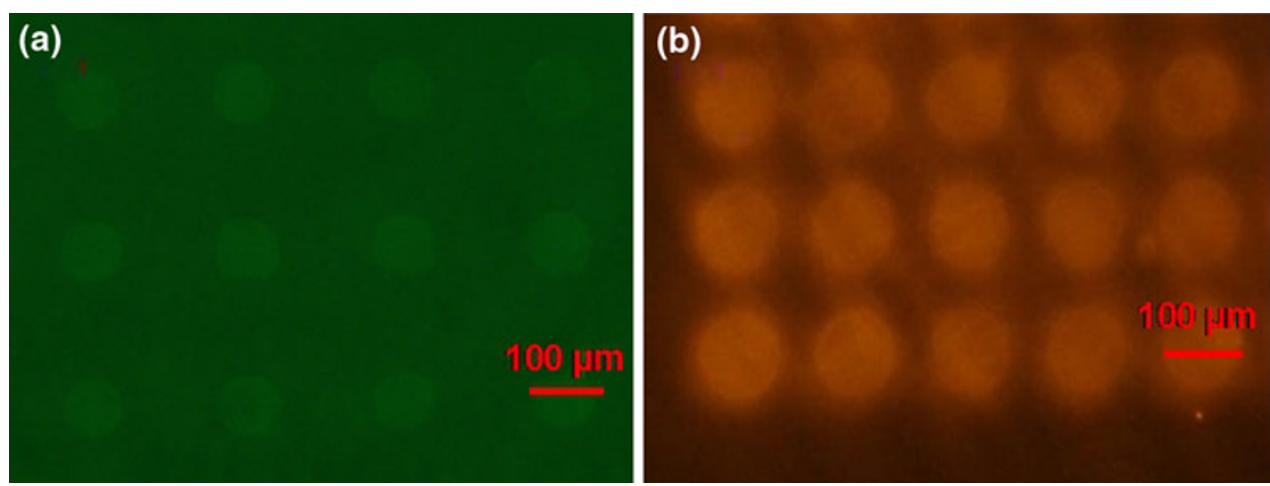
Acknowledgments We would like to acknowledge Ellen Blinka, Kathryn Loeffler for their initial contributions to the micro-contact printing technology, and Dr. Tony Hu for providing the expertise on nanoporous membranes design. We gratefully acknowledge the support of the UT Austin Undergraduate Research Fellowship, and the Microelectronics Research Center.

Open Access This article is distributed under the terms of the Creative Commons Attribution License which permits any use, distribution and reproduction in any medium, provided the original author(s) and source are credited.

\section{References}

Bernard A, Renault JP, Michel B, Bosshard R, Delamarche E (2000) Microcontact printing of proteins. Adv Mater 12:1067-1070

Blinka E, Loeffler K, Hu Y, Gopal A, Hoshino K, Lin K, Liu X, Ferrari M, Zhang XJ (2010) Enhanced microcontact printing of proteins on nanoporous silica surface. IOP Nanotechnol 21:415302

Crozatier C, Le Berre M, Chen Y (2006) Multi-colour micro-contact printing based on microfluidic network inking. Microelectron Eng 83:910-913

Ghosh M, Alves C, Tong Z, Tettey K, Konstantopoulos K, Stebe KJ (2008) Multifunctional surfaces with discrete functionalized regions for biological applications. Langmuir 24(15):8134-8142

Hu Y, Bouamrani A, Tasciotti E, Li L, Liu X, Ferrari M (2009) Tailoring of the nanotexture of mesoporous silica films and their functionalized derivatives for selectively harvesting low molecular weight protein. ACS Nano 4:439-451
Inerowicz HD, Howell S, Regnter FE, Reifenberger R (2002) Multiprotein immunoassay arrays fabricated by microcontact printing. Langmuir 18:5263-5268

Kumar A, Biebuyck HA, Whitesides GM (1994) Patterning selfassembled monolayers: applications in materials science. Langmuir 10(5):1498-1511

Lee KB, Park SJ, Mirkin CA, Smith JC, Mrksich M (2002) Protein nanoarrays generated by dip-pen nanolithography. Science 295:1702-1705

Li Y, Song C, Zhang K, Wang M, Yang K, Yang A, Jin B (2008) Establishment of a highly sensitive sandwich enzyme-linked immunosorbent assay specific for ovomucoid from hen's egg white. J Agric Food Chem 56(2):337-342

Pattani VP, Li C, Desai TA, Vu TQ (2008) Microcontact printing of quantum dot bioconjugate arrays for localized capture and detection of biomolecules. Biomed Microdevices 10:367-374

Rolland JM, Apostolou E, De Leon MP, Stockley CS, O'Hehir RE (2008) Specific and sensitive enzyme-linked immunosorbent assays for analysis of residual allergenic food proteins in commercial bottled wine fined with egg white, milk, and nongrape-derived tannins. J Agric Food Chem 56:349-354

Schmid H, Michel B (2000) Siloxane polymers for high-resolution, high-accuracy soft lithography. Macromolecules 33(8):30423049

Stephan O, Vieths S (2004) Development of a real-time PCR and a sandwich ELISA for detection of potentially allergenic trace amounts of peanut (Arachis hypogaea) in processed foods. J Agric Food Chem 52:3754-3760

Sun J, Dong T, Zhang Y, Wang S (2010) Development of enzyme linked immunoassay for the simultaneous detection of carbaryl and metolcarb in different agricultural products. Analytica Chimica Acta 666:76-82 